\title{
A GESTÃO DE RESÍDUOS EM POSTOS DE ABASTECIMENTO DE COMBUSTÍVEL
}

\section{WASTE MANAGEMENT IN THE POSTS OF THE SUPPLY OF FUEL}

\author{
Daniel Benitti Lorenzett ${ }^{1}$; Marivane Vestena Rossato ${ }^{2}$ \\ ${ }^{1}$ Universidade Federal de Santa Maria - UFSM - Santa Maria - Brasil \\ dlorenzett@gmail.com \\ ${ }^{2}$ Universidade Federal de Santa Maria - UFSM - Santa Maria - Brasil \\ marivavest@gmail.com
}

\begin{abstract}
Resumo
As questões relativas aos problemas ambientais, apesar de antigas, vêm tornando-se cada vez mais presente na vida da população mundial. Em função das mais variadas catástrofes naturais que estão a ocorrer em todo o mundo surgem na população um anseio por sustentabilidade. Nesse enfoque, as empresas devem adotar novas formas de interagir com o meio ambiente, para garantir a continuidade de seus negócios. É o caso dos postos de combustíveis, que são empresas potencialmente poluidoras, em função dos produtos comercializados e dos resíduos gerados em suas atividades. Nesse sentido, este trabalho buscou verificar qual é o destino dado aos residuos e efluentes gerados nas atividades desenvolvidas pelos postos de abastecimento de combustiveis. Para o desenvolvimento do trabalho foi realizado um estudo de caso, junto a um posto de combustiveis, localizado na cidade de Santa Maria - RS, onde foi empregada a técnica de observação aliada à técnica da entrevista estruturada. Os resultados revelaram que o posto de combustível estudado gera vários resíduos como: vapores tóxicos, lodo tóxico, flanelas e estopas contaminadas, óleo queimado, filtros usados, embalagens de lubrificantes e efluentes líquidos. Contudo, pôde também ser observado que estes resíduos são eliminados, praticamente em sua totalidade, de forma correta, através da gestão de resíduos, pelo seu tratamento ou retorno, quando possivel, ao fabricante para reciclagem.
\end{abstract}

Palavras-chave: postos de combustível; gestão de resíduos; meio ambiente.

\section{Introdução}

As questões relativas aos problemas ambientais, apesar de antigas, vêm tornando-se cada vez mais presentes na vida da população mundial. Em face à destruição cada vez mais ampla do patrimônio natural da humanidade, os governos estão tomando partido nessa questão na tentativa de remediar o perigo iminente em que o planeta se encontra. É fato, que por muitos anos, o homem, vem degradando o planeta e retirando dele, de forma abusiva e irracional o subsídio para manter as 
relações sociais tal como elas são hoje, afetando sem a menor preocupação o solo, as águas e o ar, bem como as demais formas de vida que habitam o planeta.

É perante essa situação, de degradação do meio ambiente, que hoje pode-se observar nos noticiários, diariamente, as mais variadas catástrofes naturais, que ocorrem em todo o mundo. As enchentes, as secas, terremotos, o efeito estufa, deslizamentos, mortes. Tais eventos, de ordem ambiental, têm se tornado realidades presentes na vida das pessoas em todo o planeta. Assim, surge nessa população, um anseio por sustentabilidade, por viver mais harmoniosamente com o meio ambiente, e é em função disso que as pessoas passam a exigir mais das empresas que interagem com o meio ambiente, principalmente aquelas que são potencialmente poluidoras, como é o caso dos postos de combustíveis, cujas atividades caracterizam-se como sendo de alto risco para o meio ambiente.

Diante dessa nova tendência mundial, as empresas começam a se adaptar, interagindo com o meio ambiente de forma mais responsável, reduzindo os níveis de poluição e emissão de resíduos e recuperando o meio ambiente degradado, no intuito, não somente, de manutenção do meio, mas principalmente para melhorar a visão da sociedade com relação a suas práticas, pois a gestão ambiental, em função dessas novas tendências, apresenta-se como uma excelente ferramenta não somente para melhorar as condições ambientais, mas também como forma de concorrência, uma vez que o público consumidor apoiará as empresas que estiverem mais engajadas com a proteção do meio ambiente.

As empresas, perante uma população que clama por sustentabilidade, estão tentando se adequar, principalmente no que diz respeito à questão dos resíduos e efluentes gerados por suas atividades. Nesse sentido, as empresas atuantes no segmento de abastecimento de combustíveis, se comprometem com essa questão, para garantir a continuidade de seus negócios empresariais, tendo a gestão de resíduos como uma ferramenta para obtenção do sucesso no caminho a sustentabilidade, através de seus mecanismos para o controle, preservação e recuperação ambiental. Este segmento empresarial vem investindo em proteção ambiental e tentando se adequar de forma a tornar essa atividade menos agressiva ao meio ambiente.

De acordo com a Federação Nacional do Comércio de Combustíveis e Lubrificantes FECOMBUSTÍVEIS (s/d, n/p):

a questão ambiental ganha cada vez mais importância no dia-a-dia dos postos revendedores, que precisam atender às exigências da Resolução do CONAMA nº 273 e de legislações estaduais específicas. Dessa forma, não estão apenas evitando multas e outras punições, mas também fazendo sua parte na preservação do meio ambiente e evitando gastos futuros com problemas de passivo ambiental.

No Brasil, a legislação pertinente à atividade de armazenamento e distribuição de combustível data do ano 1997, com a edição da Resolução do Conselho Nacional do Meio 
Ambiente (CONAMA) no. 237/97, que cita a atividade como sendo sujeita ao licenciamento ambiental. Na sequência, ainda em 1997, a Fundação Estadual de Proteção Ambiental (FEPAM), iniciou, em nível de Rio Grande do Sul, um programa de regularização dessas atividades, junto aos sindicatos dos distribuidores, operadores, transportadores e revendedores de combustíveis.

Mais recentemente, o CONAMA, publicou a Resolução $n^{\circ}$. 273/2000, com a finalidade principal de padronizar os procedimentos e o licenciamento das atividades que possuem armazenagem de combustíveis, como os postos de gasolina e Transportadores-RevendedoresRetalhistas (TRR).

Estas resoluções do CONAMA constituíram a base legal mais importante, para o licenciamento ambiental da atividade. Entretanto, há que se observar, também, as normas técnicas expedidas pela Associação Brasileira de Normas Técnicas (ABNT), e a legislação estadual específica de cada Estado.

Ficou explícito, assim, a necessidade de normatização das atividades que oferecem riscos ao meio ambiente, da presença dos órgãos fiscalizadores e de efetiva fiscalização e autuação daqueles que não cumprem as determinações legais.

As empresas devem se posicionar de maneira responsável perante a questão ambiental, adotando programas de gestão ambiental, principalmente quanto à emissão de resíduos, atuando de maneira sustentável, não só pela legislação que está cada vez mais abrangente e restritiva, mas também pela crescente conscientização dos consumidores que vêm exigindo cada vez mais da responsabilidade socioambiental dessas empresas.

A partir dessa contextualização, evidenciou-se a preocupação da interação da empresa com o meio ambiente no setor de armazenamento e distribuição de combustíveis, devendo ele adequar-se às normas estabelecidas pelos órgãos competentes.

Nesse enfoque, é de vital importância que essas empresas adiram a um sistema de disposição final dos resíduos gerados pela atividade, de forma a evitar sérios prejuízos financeiros, podendo até culminar com o fechamento do estabelecimento, seja por pressão social seja por intervenção da justiça.

A partir da contextualização realizada, consolida-se a seguinte questão-problema: quais são as formas de tratamento ou destino dado aos resíduos sólidos e efluentes gerados pelas atividades desenvolvidas por um posto de abastecimento de combustível localizado no município de Santa Maria - RS?

Nesse contexto, pretendeu-se chamar atenção para a questão ambiental, dos rumos que ela vem tomando, em face às catástrofes que estão ocorrendo em todo o mundo, em função da má utilização dos recursos naturais e da emissão desenfreada de resíduos potencialmente poluidores no meio ambiente, principalmente das medidas que estão sendo adotadas pelas empresas que 
desenvolvem a atividade de comércio de combustíveis, da forma como elas vêm procedendo para eliminação dos resíduos gerados, das medidas que estão sendo tomadas em prol do meio ambiente.

Diante às questões apontadas, justificou-se a necessidade do estudo realizado, com relação aos destinos dados aos resíduos e efluentes gerados pelas atividades de um posto de abastecimento de combustíveis, uma vez que, a partir da adequada gestão de resíduos, as empresas desse segmento estariam contribuindo, efetivamente, para o controle e preservação ambiental. Pretendeu-se, basicamente, verificar qual é o destino dos resíduos gerados por este segmento. Especificamente foi caracterizado o funcionamento e identificados os procedimentos inerentes à atividade do posto de abastecimento de combustível; identificado de que forma ocorre à interação da entidade com o meio ambiente; levantadas as medidas de gestão de resíduos que estão sendo adotadas no posto de abastecimento de combustível.

O estudo foi estruturado para ser apresentado em quatro seções, além desta introdução, onde o capítulo dois trata do referencial teórico. O capítulo três contém a metodologia utilizada para realização da pesquisa. O capítulo quatro, por sua vez, contempla os resultados e discussões inerentes ao tema. Por último, o capítulo cinco, que apresenta as considerações finais, as conclusões que puderam ser alcançadas mediante o estudo, bem como as sugestões para novas pesquisas na área, de forma a dar continuidade ao trabalho aqui desenvolvido.

\section{Referencial teórico}

\subsection{O Ramo de postos de combustíveis}

É o ramo de atividade empresarial que trabalha basicamente o comércio varejista de combustíveis fosseis e/ou bicombustíveis.

Para Barros (2006) o petróleo é a maior fonte de energia fóssil. Além de ser o mais importante e indispensável dos combustíveis fosseis.

Segundo Barros (2006), os transportes no Brasil são predominantemente rodoviários, dependendo basicamente de combustíveis fósseis e bicombustíveis para manter o ciclo econômico da nação. Fica demonstrada, dessa forma, a importância da cadeia de postos de abastecimento de combustíveis, estrategicamente, disposta em todo território nacional.

O órgão regulador das atividades que integram a indústria do petróleo e gás natural e a dos bicombustíveis no Brasil é a Agência Nacional do Petróleo, Gás Natural e Bicombustível (ANP), devendo quem desejar desenvolver estas atividades sujeitar-se as normas por ela impostas.

É de competência do CONAMA legislar sobre a atividade e da FEPAM licenciar e fiscalizar o cumprimento das normas estabelecidas. Cabendo às prefeituras municipais a questão da 
permissão para o funcionamento dos postos, ou seja, identificar os locais adequados ao desenvolvimento dessa atividade.

Para Santos (2005), o ramo de postos revendedores de combustível (PRC) pode ser dividido em duas categorias: a de postos cidade e a de postos estrada, em função das atividades neles desenvolvidas. O primeiro é mais voltado para atender às necessidades da população urbana, enquanto o segundo seria mais voltado a atender às necessidades dos viajantes e dos caminhoneiros. Isso implica diretamente na disposição do estabelecimento, pois enquanto o primeiro localiza-se em perímetro urbano e possui estruturas menores, o segundo concentra-se geralmente junto às estradas e possui uma estrutura relativamente maior em função até da disponibilização de estacionamentos para que os caminhoneiros possam pernoitar.

Como podem ser observados na Figura 1, os postos de combustíveis possuem basicamente as seguintes instalações: a unidade de abastecimento de veículos (bomba de gasolina), os tanques de combustíveis (geralmente enterrados), os pontos de descarga de combustíveis, onde os carrostanques fazem o reabastecimento dos PRCs, o tanque para recolhimento e guarda de óleo lubrificante usado (geralmente enterrados), as tubulações enterradas que comunicam o ponto de descarga com o reservatório e este com as bombas de abastecimento, as edificações para escritório e arquivo morto, a loja de conveniência, o centro de lubrificação e o centro de lavagem, a unidade de filtragem de diesel, o sistema de drenagens oleosas e fluviais e os equipamentos de proteção e controle de derrames e vazamentos de combustíveis, bem como de segurança quanto a incêndios e explosões (SANTOS, 2005).

Figura 01 - Esquema típico de um Posto Revendedor de Combustível

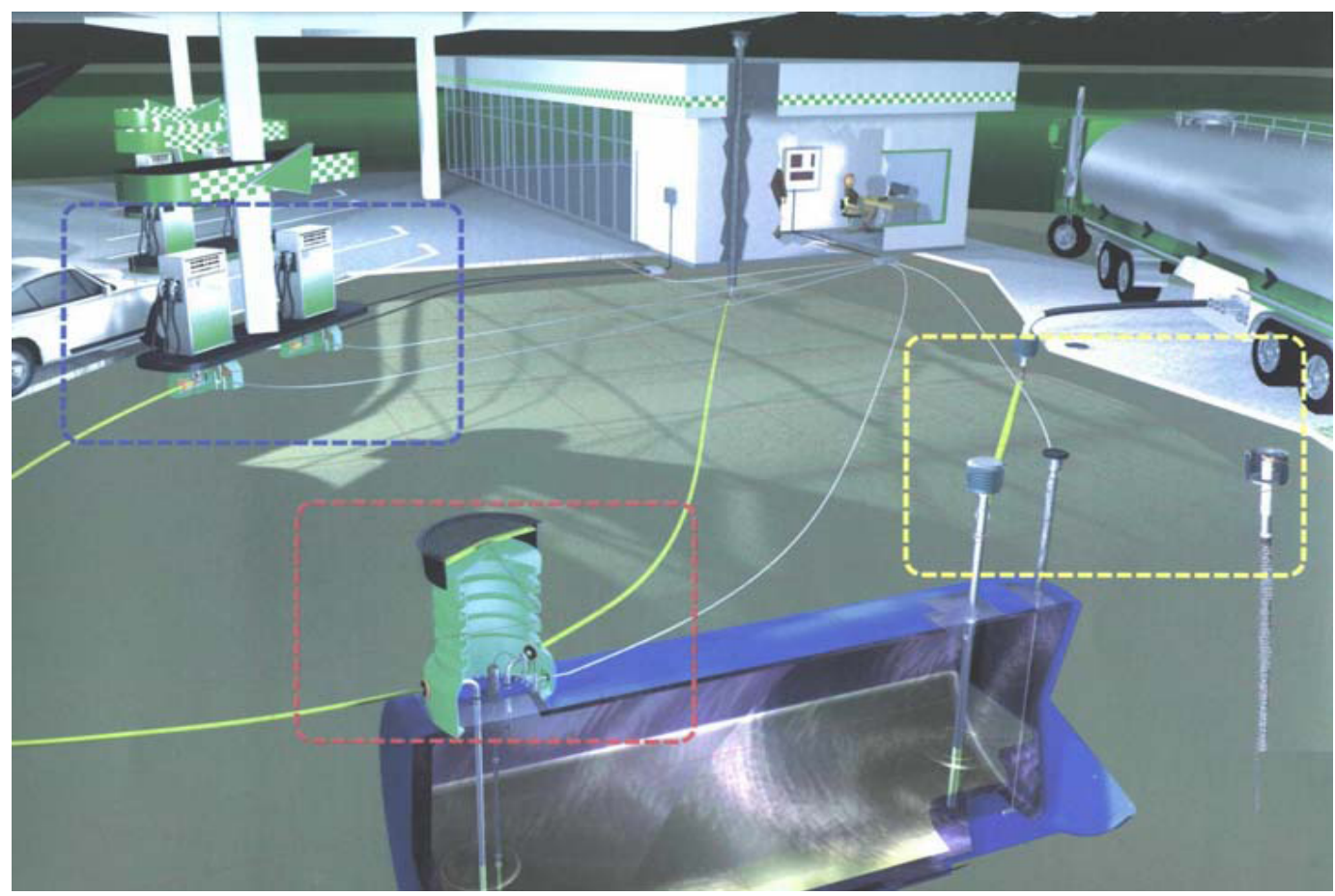

Fonte: Santos (2005, apud Ecoteste, 2005). 
Ainda, segundo Santos (2005, P. 74), as atividades mais frequentes em um posto de combustíveis são as seguintes:
a) recebimento de produto, via carros-tanques de combustíveis;
b) armazenamento dos combustíveis em tanques enterrados;
c) abastecimento dos veículos;
d) operação do sistema de drenagem oleosa segregada da fluvial;
e) troca de óleo lubrificante dos motores dos veículos;
f) lavagens de veículos;
g) operação da loja de conveniência / escritórios / arquivo morto.

Tais atividades, por manipularem produtos químicos (combustíveis fósseis), são consideradas potencialmente poluidoras, podendo, impactar o meio ambiente, em função dos resíduos gerados.

Os principais resíduos gerados nessas atividades consistem em vapores de combustíveis, flanelas e estopas contaminadas, efluentes líquidos, como águas oleosas, filtros usados, óleo queimado, lodo toxico das caixas separadoras de água e óleo e embalagens de lubrificantes.

Segundo Santos, (2005), os impactos ambientais causados por esses resíduos provenientes da atividade de posto de combustível podem ser controlados e/ou evitados, desde que, se invista em equipamentos mais adequados, implementando novas tecnologias menos impactantes, para controle ambiental, promovendo um melhor desempenho ambiental operacional ao não provocar incidentes dessa natureza.

Nesse enfoque, a gestão de resíduos, torna-se uma aliada no combate aos impactos ambientais, consistindo numa importante ferramenta para o sucesso do desempenho ambiental operacional.

Com relação aos sistemas de gestão, Santos (2005), diz que o simples fato dos postos de combustíveis possuírem um sistema de gestão ambiental e aplicá-lo evitaria uma série de problemas de ordem ambiental. Para tanto, ele sugere a adoção de um sistema simplificado de Gestão Ambiental para os postos revendedor de combustíveis, sintetizado nas seguintes diretrizes:

1) Liderança e Comprometimento: o responsável pela organização deve ser responsável e comprometido com as diretrizes do sistema de gestão ambiental.

2) Objetivos Estratégicos: aqui as metas, programas e planos para alcançar os objetivos devem ser registrados. Os objetivos devem seguir os seguintes tópicos: gerenciamento de combustíveis, gerenciamento de efluentes (sólidos, líquidos e gasosos), administração predial e limpeza geral, gerenciamento de água, energia e ruído e gerenciamento de segurança geral.

3) Organização e Responsabilidades: devem ser definidos os papéis e responsabilidade de cada membro da equipe, com suas respectivas tarefas descritas e garantida a sua capacidade via treinamento. 
4) Gerenciamento dos Riscos Ambientais e seus Efeitos: para cada atividade desenvolvida deve ser feita uma avaliação dos riscos ambientais envolvidos, identificando os impactos sobre o meio ambiente.

5) Verificação e Controle Operacional: deve ser mantido um monitoramento e acompanhamento permanente em todas as atividades.

6) Análise da Administração: por fim, deve ser feita anualmente uma revisão do Sistema de Gestão Ambiental, para verificar as oportunidades de melhorias e necessidade de alterações no sistema.

Segundo Santos (2005), o simples fato da existência desse programa de ações na entidade não é o suficiente para que se possa evitar a ocorrência dos impactos ambientais, entretanto a simples inclusão dessas premissas no decorrer das atividades pode sim, impedir a contaminação do meio ambiente e auxiliar a promover o bem estar ambiental local.

\subsection{Legislação ambiental aplicável aos postos de combustíveis}

Desde a Lei Federal $n^{\circ}$ 6.938/81, regulamentada pelo Decreto Federal n. ${ }^{\circ}$ 99.274/90, a atividade de comércio varejista de combustíveis (postos de gasolina) está submetida à legislação ambiental, sendo citada, também, como atividade sujeita ao licenciamento ambiental pela Resolução do Conselho Nacional do Meio Ambiente - CONAMA n ${ }^{\circ}$ 237/97 e mais recentemente pela resolução CONAMA n ${ }^{0}$ 273/2000, que trata especificamente da padronização e licenciamento das atividades que possuem reservatórios e armazenamento de combustíveis, constituindo a mais abrangente e mais importante legislação referente à tratativa.

No Rio Grande do Sul, desde 1997, todas as atividades relativas ao licenciamento e fiscalização quanto ao cumprimento das normas estabelecidas pelas resoluções CONAMA são de competência da FEPAM.

Fica determinado pela Resolução do CONAMA no $273 / 2000$, em seu art. $1^{\circ}$ que todas as atividades referentes ao setor de armazenamento e distribuição de combustíveis, deverão ser realizadas em conformidade com as normas técnicas expedidas pela ABNT ou pelo órgão ambiental competente.

As NBR da ABNT que dispõe sobre a gestão de resíduos gerados pela atividade de posto de abastecimento de combustível são: NBR 12235 e NBR 10004, a primeira normatiza a forma de armazenamento dos resíduos gerados na atividade e a segunda dispõe sobre as embalagens de produtos consideradas como resíduos perigosos e sua obrigatoriedade de devolução ao fornecedor destes produtos. 


\subsection{A Logística reversa como forma de gestão de resíduos}

Segundo Leite (2006), quando se fala em logística reversa (LR) deve-se imediatamente pensar no inverso da logística empresarial, que consiste no transporte, movimentação de materiais, armazenagem, processamento de pedidos e gerenciamento de informações, envolvendo o ciclo de atividades que acompanham o produto, desde sua matéria-prima até o consumidor final. Deve-se, portanto, pensar nas atividades de gerenciamento do retorno de produtos do consumidor ao fornecedor, ou seja, da disposição de embalagens e resíduos, da reciclagem, da remanufatura e do reuso de materiais.

Para Leite (2006, p. 16), entende-se por logística reversa:

a área da logística empresarial que planeja, opera e controla o fluxo e as informações logísticas correspondentes, do retorno dos bens de pós-venda e de pós-consumo ao ciclo de negócios ou ao ciclo produtivo, por meio dos canais de distribuição reversos, agregandolhes valor de diversas naturezas: econômico, ecológico, legal, logístico, de imagem corporativa, entre outros.

Infere-se daí, que a logística reversa consiste no processo de retorno dos produtos, de seus resíduos, ou sucatas do consumidor para o fornecedor, para a reciclagem ou para o reuso.

Para Leite (2006), quando os bens são devolvidos por defeitos, término de validade ou estoques excessivos, eles farão parte da cadeia pós-venda e serão encaminhados para mercados secundários. Já, quando eles são utilizados e posteriormente são descartados, farão parte da cadeia de pós-consumo, onde poderão ser reciclados, remanufaturados, reutilizados ou dispostos em aterros sanitários, dependendo de sua condição.

Dentro de se contexto pode-se inferir que a logística reversa é de grande valia a gestão de resíduos em postos de combustíveis, pois através de suas premissas pode-se dar o destino correto aos resíduos gerados nessas atividades.

\section{Metodologia da Pesquisa}

Segundo Marconi e Lakatos (2005), o procedimento metodológico consiste numa série de regras com a finalidade de resolver determinado problema ou, ainda, explicar um fato por meio de hipóteses ou teorias que devem ser testadas experimentalmente podendo ser comprovadas ou refutadas. Sendo assim, nesta sessão estão expostos os métodos, técnicas e materiais mais adequados utilizados para o desenvolvimento do tema. Aqui, também estão descritos os passos operacionais que foram realizados na pesquisa.

Quanto à abordagem da pesquisa, o trabalho foi desenvolvido mediante observação e descrição do tema. Na tentativa de entender na essência seu significado, classificou-se, portanto, 
como pesquisa qualitativa, podendo, tanto o objeto de pesquisa quanto o pesquisador, serem influenciados por sua ocorrência, uma vez que não existe certeza absoluta no que está sendo pesquisado. Preocupa-se, pois, com o nível de verdade que não pode ser quantificado.

Para Richardson (2008, p. 79) o método qualitativo "é aquele que não faz uso de procedimentos estatísticos para análise do problema, mas sim tenta entender sua natureza, através da observação e descrição, tendo por objeto situações complexas ou estritamente particulares". O que remete ao subjetivismo, tanto do objeto de pesquisa quanto do pesquisador e imprime um caráter indutivo à pesquisa.

Quanto aos objetivos da pesquisa, ela foi considerada descritiva, pois fez uso, principalmente, de técnicas padronizadas de coleta de dados. Andrade (1999, p.106), define a pesquisa descritiva como aquela onde "os fatos são observados, registrados, analisados, classificados e interpretados, sem que o pesquisador interfira neles. Isso significa que os fenômenos do mundo físico e humano são estudados, mas não manipulados pelo pesquisador”. Trata-se, portanto, da observação das situações e relações que ocorrem com o objeto estudado, sem que para isso, haja interação do pesquisador com o objeto alvo de estudo.

A pesquisa também pôde ser considerada exploratória, uma vez que tratou de um problema, ainda, pouco estudado.

Para Andrade (1999, p.106), a pesquisa exploratória será aquela que "proporcionar maiores informações sobre determinado assunto; facilitar a delimitação de um tema de trabalho".

Assim, nessa pesquisa, pretendeu-se descobrir as relações existentes entre os componentes do objeto de estudo, firmando-se, portanto, como um trabalho inicial, que fundamentará outro tipo de pesquisa.

Neste estudo de caso foi realizada a observação dos procedimentos inerentes à atividade de posto de combustível, a identificação da forma com que ocorre a interação da entidade com o meio ambiente e dos resíduos gerados pela atividade, mas principalmente foi verificado o destino final dado a estes resíduos.

Quanto à técnica de coleta de dados, foi considerado o procedimento da observação, que para Martins (2006, p.23), “ao mesmo tempo em que permite a coleta de dados das situações, envolve a percepção sensorial do observador, distinguindo-se, enquanto prática científica, da observação da rotina diária.” Constituindo-se, assim num procedimento empírico sensorial.

Ainda, para a coleta de dados, foi considerada a técnica da entrevista estruturada. Segundo Cervo e Bervian (2006, p. 46), a entrevista “... não é simples conversa. É conversa orientada para um objetivo definido: recolher, por meio do interrogatório do informante, dados para a pesquisa”. 


\section{Resultados e Discussões}

Esta seção tem por finalidade apresentar os resultados obtidos com o desenvolvimento da pesquisa, bem como as análises e interpretações pertinentes, de acordo com as normas que regem as atividades de postos de combustível.

\subsection{Procedimentos operacionais das atividades do posto de combustível}

No estabelecimento estudado são realizadas as atividades de lavagem de veículos, troca de óleo, filtros e lubrificação e de loja de conveniência, além, é claro, de armazenamento e abastecimento de combustíveis, que são as atividades principais da entidade, como é demonstrado no organograma da Figura 2.

Figura 2 - Organograma das atividades desenvolvidas no posto de combustível

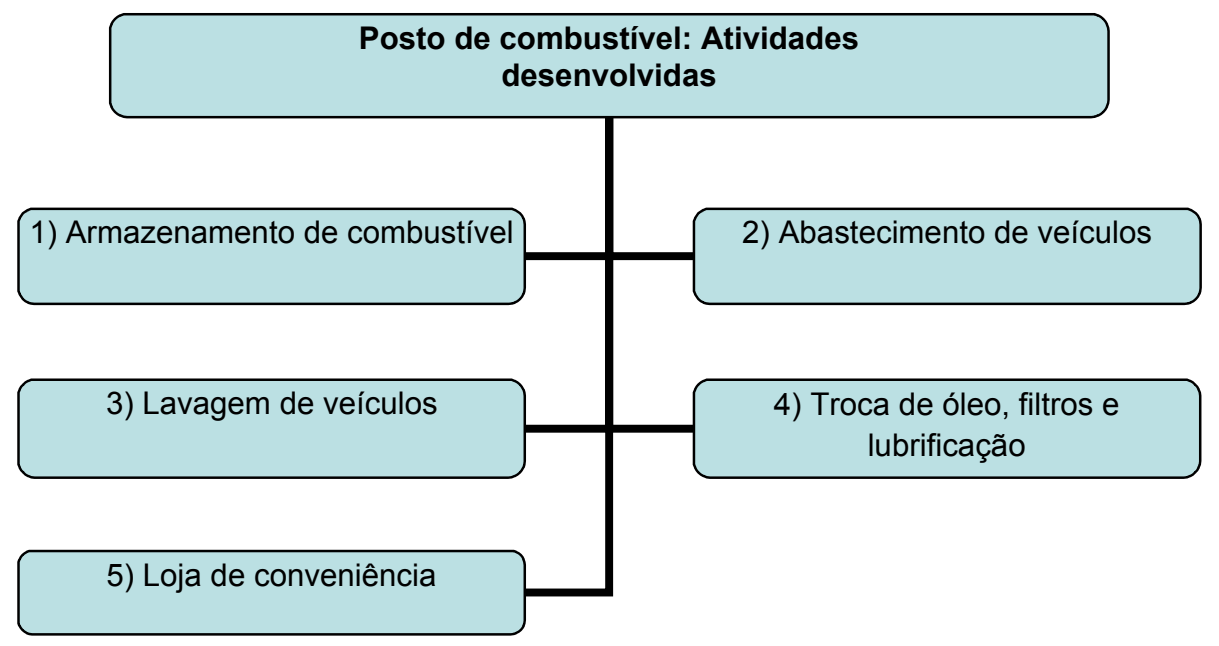

Fonte: Pesquisa de campo (2010)

Para melhor entendimento das atividades ligadas ao setor de postos de abastecimento de combustíveis, faz-se necessário, proceder a sua descrição e caracterização.

1) Atividade de armazenamento de combustível: a unidade conta com três tanques subterrâneos localizados ao lado do posto, sendo que estes tanques são ecológicos, ou seja, de PVC, com capacidade para 30 mil litros de combustível cada, sendo cada unidade subdividida em dois tanques menores de 15 mil litros, distribuídos da seguinte forma: o primeiro tanque abriga álcool e gasolina comum, o segundo estoca gasolina comum e gasolina aditivada e o terceiro tanque contém apenas óleo diesel. Ao lado dos tanques a empresa mantém dois poços de monitoramento, onde são realizados semestralmente testes para verificar a qualidade das águas subterrâneas.

2) Atividade de abastecimento de veículos: para seu desenvolvimento, são utilizadas unidades de abastecimento, as chamadas bombas de abastecimento eletrônicas. Essas bombas são automatizadas 
por valor ou por litragem, o que permite maior precisão na hora do abastecimento. As bombas também possuem, em seus bicos, um sensor que aciona quando da presença de calor excessivo ou do contato com o combustível, quando o tanque encontra-se cheio, impedindo assim o derrame de combustível e também possíveis explosões. Elas contam ainda, com um sistema interno que impede a volta de combustível para a bomba, impedindo, em caso de incêndio, que o fogo atinja maiores proporções, reduzindo a probabilidade de explosões.

Além da adoção de equipamentos mais modernos como medidas de segurança, os frentistas utilizam uma flanela para realizar o abastecimento, com a qual limpam o bico da bomba quando de sua retirada do veículo no término do abastecimento, para evitar gotejamento de combustível tanto no veículo como no piso do estabelecimento.

3) Atividade de lavagem de veículos: esta ocorre em local apropriado a esta atividade. A água utilizada para a lavagem dos veículos é proveniente de um reservatório com capacidade de estocagem para setenta e cinco mil litros, construído pelo posto de combustível para reserva e captação de água da chuva. O local é todo cercado por canaletas, que conduzem a água da lavagem diretamente para uma caixa separadora, onde os resíduos químicos são separados da água.

4) Atividade de troca de óleo, filtros e a lubrificação: as atividades ocorrem numa rampa construída especificamente para esse fim, de forma a facilitar o desenvolvimento dessa atividade com o mínimo de esforço humano, proporcionando um trabalho mais tranquilo, ágil, e seguro. É importante salientar, ainda que a condução do óleo queimado, proveniente da atividade de troca de óleo, é realizada através de tubulações, sendo, portanto, encaminhado da rampa de troca até o tanque reservatório de forma canalizada, como manda a legislação. Este local, onde são realizadas tais atividades, fica dentro de um perímetro maior, todo cercado pelas mesmas canaletas encontradas na área de lavagem, que irá conduzir os resíduos líquidos a já mencionada caixa separadora, ao passo que os resíduos sólidos e as embalagens de lubrificantes são armazenadas e passarão pelo processo de logística reversa.

5) Atividade de loja de conveniência: ela não produz alimento de tipo algum, apenas revende lanches. Toda a parte de produção dos alimentos é terceirizada e a única atividade nela realizada, além obviamente da revenda desses alimentos, consiste na lavagem dos talheres e louças utilizados para servir os alimentos aos clientes.

Vale, ainda, ressaltar que todo o perímetro das atividades do posto é cercado por canaletas, desde a área dos tanques até a pista de abastecimento, para condução dos efluentes líquidos, gerados pela atividade, para a caixa separadora de água e óleo, onde receberão tratamento adequado. 


\subsection{Interação da entidade com o meio ambiente no posto de abastecimento de combustível}

A interação com o meio ambiente comumente ocorre no decorrer das atividades operacionais diárias realizadas. Essa interação pode ser observada pelo consumo de recursos naturais e pela forma como é feito o descarte dos resíduos e efluentes gerados pela atividade, como demonstra o Quadro 1.

Quadro 1 - Interação da atividade com o meio ambiente

\begin{tabular}{|c|c|c|c|}
\hline $\begin{array}{c}\text { ATIVIDADE } \\
\text { DESENVOLVIDA }\end{array}$ & $\begin{array}{c}\text { RECURSOS } \\
\text { NATURAIS } \\
\text { CONSUMIDOS }\end{array}$ & $\begin{array}{c}\text { RESÍDUOS / } \\
\text { EFLUENTES } \\
\text { GERADOS }\end{array}$ & $\begin{array}{l}\text { DESTINO DOS } \\
\text { RESIDUOS / } \\
\text { EFLUENTES }\end{array}$ \\
\hline $\begin{array}{c}\text { Armazenamento de } \\
\text { combustível }\end{array}$ & Não consome & Vapores tóxicos & $\begin{array}{c}\text { Lançado diretamente } \\
\text { no ar }\end{array}$ \\
\hline \multirow[t]{2}{*}{$\begin{array}{c}\text { Abastecimento de } \\
\text { veículos }\end{array}$} & \multirow[t]{2}{*}{$\begin{array}{c}\text { Água da chuva para } \\
\text { limpeza }\end{array}$} & Efluentes líquidos & $\begin{array}{c}\text { Tratados e } \\
\text { eliminados no esgoto } \\
\text { comum }\end{array}$ \\
\hline & & $\begin{array}{c}\text { Flanelas utilizadas no } \\
\text { abastecimento }\end{array}$ & $\begin{array}{c}\text { São recolhidas por } \\
\text { empresa } \\
\text { especializada }\end{array}$ \\
\hline \multirow[t]{2}{*}{$\begin{array}{l}\text { Lavagem de } \\
\text { veículos }\end{array}$} & \multirow[t]{2}{*}{$\begin{array}{l}\text { Água da chuva como } \\
\text { matéria-prima }\end{array}$} & Efluentes líquidos & $\begin{array}{c}\text { Tratados e } \\
\text { eliminados no esgoto } \\
\text { comum }\end{array}$ \\
\hline & & $\begin{array}{c}\text { Flanelas, estopas e } \\
\text { esponjas utilizadas } \\
\text { nas lavagens }\end{array}$ & $\begin{array}{c}\text { São recolhidas por } \\
\text { empresa } \\
\text { especializada }\end{array}$ \\
\hline \multirow[t]{2}{*}{$\begin{array}{l}\text { Troca de óleo, filtro } \\
\text { e lubrificação }\end{array}$} & \multirow[t]{2}{*}{$\begin{array}{c}\text { Água da chuva para } \\
\text { limpeza }\end{array}$} & Efluentes líquidos & $\begin{array}{c}\text { Tratados e } \\
\text { eliminados no esgoto } \\
\text { comum }\end{array}$ \\
\hline & & $\begin{array}{l}\text { Óleo queimado, } \\
\text { filtros usados, } \\
\text { embalagens de } \\
\text { lubrificantes, flanelas } \\
\text { e estopas utilizadas } \\
\text { nas atividades }\end{array}$ & $\begin{array}{c}\text { São recolhidos por } \\
\text { empresa } \\
\text { especializada e } \\
\text { enviados para aterros } \\
\text { sanitários ou } \\
\text { reciclados }\end{array}$ \\
\hline $\begin{array}{c}\text { Loja de } \\
\text { conveniência }\end{array}$ & $\begin{array}{c}\text { Água da chuva para } \\
\text { limpeza }\end{array}$ & Efluentes líquidos & $\begin{array}{c}\text { Tratados e } \\
\text { eliminados no esgoto } \\
\text { comum }\end{array}$ \\
\hline $\begin{array}{l}\text { Tratamento dos } \\
\text { efluentes líquidos }\end{array}$ & Não consome & Lodo tóxico & $\begin{array}{l}\text { É recolhido por } \\
\text { empresa } \\
\text { especializada }\end{array}$ \\
\hline
\end{tabular}

Fonte - Pesquisa de campo (2010)

Como pode ser observado no Quadro 1, os resíduos gerados pela atividade são vapores tóxicos, efluentes líquidos, lodo tóxico da caixa separadora de água e óleo, flanelas e estopas contaminadas, filtros usados e embalagens de lubrificantes. 
É importante ressaltar que caso estes resíduos não sejam dispostos de maneira correta certamente acabarão por afetar não somente ao meio ambiente, mas também a saúde humana.

\subsection{As medidas de gestão de resíduos pelo posto de combustível}

As medidas de gestão ambiental adotadas são basicamente medidas de controle e prevenção ambiental, e em geral estão intimamente relacionadas às atividades desenvolvidas no posto de combustível.

Com relação aos vapores tóxicos são feitas as manutenções nas válvulas dos tanques de combustíveis periodicamente como determina a legislação, entretanto, por falta de legislação que regulamente e até por falta de tecnologias específicas, os gases emitidos pelos suspiros dos tanques reservatórios de combustível são liberados diretamente na atmosfera, sem que haja o devido tratamento.

Os efluentes líquidos gerados nas atividades são tratados em uma caixa separadora de água e óleo. Nesse tratamento são removidos da água os resíduos de combustíveis e lubrificantes, restando no final do processo uma água barrenta, imprópria para reutilização, que é lançada no esgoto comum. Os resíduos retirados da água compõem, agora, uma espécie de lodo tóxico, que é recolhido por uma empresa especializada, que fará a correta disposição final desse resíduo.

As flanelas e estopas contaminadas, assim como os filtros usados são armazenados pelo posto para serem recolhidos, posteriormente, por empresa especializada, que fará a correta disposição final desse resíduo. Já as embalagens de lubrificantes são armazenadas para posterior coleta pelo fabricante do produto, para que se possa proceder a reciclagem desses materiais.

Estes processos de gestão ambiental fazem parte da administração global de toda e qualquer empresa, que prima, um mínimo possível, pelo equilíbrio ambiental. Assim, o processo de excelência na gestão de resíduos, torna-se mais completo a partir do desenvolvimento de medidas de gestão ambiental que conduzem a qualidade do meio ambiente, proporcionando maior qualidade da gestão organizacional.

\section{Considerações finais}

Atualmente, se vive uma fase onde a questão ambiental está ganhando força, os órgãos ambientais estão cada vez mais atuantes, e a legislação cada vez mais rigorosa.

Este trabalho teve por foco principal a verificação das medidas de gestão de resíduos em postos de combustíveis. Buscou-se verificar quais os resíduos gerados por essas atividades e qual o destino final dado a tais resíduos. 
No decorrer deste trabalho foi observado que o posto de combustível, alvo do estudo, no decorrer de suas atividades, gera resíduos como: vapores tóxicos, efluentes líquidos, lodo tóxico da caixa separadora de água e óleo, flanelas e estopas contaminadas, filtros usados e embalagens de lubrificantes.

Identificou-se que a entidade interage com o meio ambiente através do desenvolvimento de suas atividades, uma vez que está em constante contato com a água, com o solo e com o ar, podendo, em caso de descuidos, vir a causar danos ambientais.

Constatou-se, quanto às medidas de gestão de resíduos, que o estabelecimento estudado vem adotando todas as medidas possíveis, além de manter uma preocupação constante com a questão ambiental.

Para futuras investigações, sugere-se estudar de que forma a legislação ambiental pode auxiliar na gestão de resíduos através dos seus mecanismos de restrição aplicados às empresas do segmento de postos de combustível.

Embora os processos de gestão de resíduos, identificados no estudo, façam parte das medidas de gestão ambiental de qualquer empresa, desse segmento, que demonstre um mínimo de interesse pela proteção do meio ambiente, isso não significa dizer que todas essas empresas agem com excelência nessa gestão, pois não se trata apenas da existência das medidas, mas sim de sua operacionalização, do zelo com que os processos são realizados para garantir que se efetive a excelência da gestão de resíduos, culminando com a ascensão da qualidade administrativa global organizacional.

\begin{abstract}
The Issues relating to environmental problems, although old, are becoming ever more presents in people's lives worldwide. Because of the natural disasters most varied that are occurring around the world, arise in population, sustainability wish. In this approach, companies must adopt new ways to interact with the environment, to ensure the continuity of their business. This is the case of gas posts, which are potentially polluting companies, because of the products sold and the waste generated in their activities. Accordingly, this study tried to ascertain what happens to waste and effluents generated by activities carried by gas stations of fuel. To development the work was performed a case study, in a petrol post, located in Santa Maria-RS, where he was employed the technique of observation coupled with the structured interview technique. The results revealed that the studied petrol post, generates various wastes such as: toxic fumes, toxic sludge, flannels and tow contaminated, burned oil, used filters, packaging of lubricants, and liquid effluents. However it can also be observed that these residues are deleted, virtually in its entirety, correctly, through the management of waste, by its treatment or return to manufacturer, whenever possible, for recycling.
\end{abstract}

Keywords: gas stations; waste management; environment. 


\section{Referências}

ANDRADE, Maria Margarida de. Introdução a metodologia do trabalho científico: elaboração de trabalhos na graduação. 4. ed. São Paulo: Atlas, 1999.

BARROS, Paulo Eduardo Oliveira de. Diagnostico ambiental para postos de abastecimento de combustíveis -

DAPAC. Itajaí: Universidade do Vale do Itajaí, 2006.

CERVO, Amado Luiz; BERVIAN, Pedro Alcino. Metodologia cientifica. 5. ed. São Paulo: Pearson Prentice Hall, 2006.

CONAMA. Resoluções: resolução n 273 de 29 de novembro de 2000. [s.l.]: CONAMA, 2000. Disponível em: $<\mathrm{http}$ //www.mma.gov.br/port/conama/res/res00/res27300.html>. Acesso em: 25 de Set. 2009.

FECOMBUSTÍVEIS. Meio Ambiente. Rio de Janeiro: Fecombustíveis, [s/d]. Disponível em: $<$ http://www.fecombustiveis.org.br/meio-ambiente.html $>$. Acesso em: 28 de Nov. 2009.

LEITE, Paulo Roberto. Logística reversa: meio ambiente e competitividade. 2. Reimpressão. São Paulo, SP: Pearson Prentice Hall, 2006.

LODI, João Bosco. A entrevista: teoria e prática. 2. ed. São Paulo: Pioneira, 1974.

MARCONI, Maria de Andrade; LAKATOS, Eva Maria. Fundamentos de metodologia científica. 6. ed. São Paulo: Atlas, 2005.

RICHARDSON, Roberto Jarry. Pesquisa social: métodos e técnicas. 3. ed. 9. Reimpressão. São Paulo: Atlas, 2008.

SANTOS, Ricardo José Shamá dos. A gestão ambiental em posto revendedor de combustíveis como instrumento de prevenção de passivos ambientais. 2005. 217f. Dissertação (Mestrado em Sistemas de Gestão do Meio Ambiente) Universidade Federal Fluminense, Niterói, 2005.

SEVERINO, Antônio Joaquim. Metodologia do trabalho científico. 23. ed. São Paulo: Cortez Editora, 2007.

TRUJILlO FERRARI, A. Metodologia da pesquisa científica. São Paulo: McGraw-Hill do Brasil, 1982.

\section{Dados dos autores:}

Nome completo: Daniel Benitti Lorenzett

Filiação institucional: Universidade Federal de Santa Maria (UFSM)

Departamento: Graduação em Ciências Contábeis

Função ou cargo ocupado: Graduando

Endereço completo para correspondência: Rua Mal. Floriano Peixoto, 1184, $6^{\circ}$ andar, Centro Santa Maria - RS.

Telefones para contato: (55) 32209260

e-mail:dlorenzett@gmail.com

Nome completo: Marivane Vestena Rossato

Filiação institucional: Universidade Federal de Santa Maria (UFSM)

Departamento: Graduação em Ciências Contábeis

Função ou cargo ocupado: Professor Adjunto 
Endereço completo para correspondência: Rua Mal. Floriano Peixoto, 1184, $6^{\circ}$ andar, Centro Santa Maria - RS.

Telefones para contato: (55) 32209260

e-mail:marivavest@gmail.com 